\title{
Effect of Respiratory Rehabilitation Nursing Interventions on Acute Exacerbation Symptoms of Chronic Obstructive Pulmonary Disease
} Among Hospitalized Geriatric Patients

\author{
Asmaa Mahmoud Ali Ibrahim, Assistant Lecturer \\ Gerontological Nursing, Faculty of Nursing, Alexandria University \\ Moshera Mostafa El-Geneidy, Professor \\ Gerontological Nursing, Faculty of Nursing, Alexandria University \\ Hanaa Abou El-soued Hussein Ahmed, Assistant Professor \\ Gerontological Nursing, Faculty of Nursing, Alexandria University \\ * Corresponding author: Asmaa Mahmoud Ali Ibrahim \\ E-mail: asmma_ali@alexu.edu.eg
}

\begin{abstract}
Acute Exacerbation of Chronic Obstructive Pulmonary Disease (AECOPD) is characterized by a sudden worsening of COPD symptoms such as dyspnea, cough, increased sputum production, and exercise intolerance. Implementation of respiratory rehabilitation nursing interventions is crucial in the management of AECOPD in geriatric patients. Objective: Determine the effect of respiratory rehabilitation nursing interventions on acute exacerbation symptoms of chronic obstructive pulmonary disease among hospitalized geriatric patients. Setting: Two units; the respiratory disorders unit and the geriatric medicine unit affiliated to the Main University Hospital in Alexandria, Egypt. Subjects: A purposive sampling of fifty (50) geriatric patients with AECOPD was recruited. The selected subjects were divided into two equally matched groups; one study group and one control group. Tools: Six tools were used for data collection: Short Portable Mental Status Questionnaire (SPMSQ), Geriatric Depression Scale Short-Form (GDS-SF), Socio-demographic and Clinical Data of Hospitalized Geriatric Patients with AECOPD Structured Interview Schedule, The Simplified Cough Score (SCS), The Modified Borg Scale for Perceived Dyspnea, and 1-Minute Sit-to-Stand (1-MSTS) Test. Results: After the implementation of the proposed nursing interventions, a statistically significant improvement was observed in all acute exacerbation symptoms of COPD among the subjects in the study group when compared to the control group who received routine hospital care only. Greater and more positive effect size was detected on the severity of dyspnea than the severity of other AECOPD in the study group. Conclusion: The proposed respiratory rehabilitation nursing interventions proved to be effective in reducing the severity of AECOPD symptoms among hospitalized geriatric patients. Recommendations: It is critical for geriatric patients with AECOPD to receive respiratory rehabilitation nursing interventions as soon as possible in order to reduce the severity of associated symptoms. This is through educating geriatric COPD patients and their families on preventative measures to avoid the occurrence of AECOPD. This can be accomplished by well-trained nurses in different clinical settings.
\end{abstract}

Keywords: Respiratory Rehabilitation; Nursing Interventions; Acute Exacerbation Symptoms, Chronic Obstructive Pulmonary Disease; Geriatric Patients.

\section{Introduction}

Chronic obstructive pulmonary disease (COPD) is a preventable and treatable disorder characterized by persistent and usually worsening airflow restriction (Global Initiative for Chronic Obstructive
Lung Disease (GOLD), 2020). In geriatric patients, COPD is complicated by frequent and recurrent acute exacerbations of symptoms, resulting in significant morbidity and mortality, as well as an increased burden and cost on health care services (Liao et al., 2015). Acute exacerbation of 
COPD (AECOPD) is defined as a natural course of disease event characterized by a sudden worsening of COPD symptoms, mainly dyspnea, cough, increased sputum production, and low exercise tolerance. These symptoms persist for more than 48 hours and typically lead to decreased lung function, increased occurrence of respiratory failure, and even death (GOLD, 2020; Ambali and Jayanth, 2019).

Dyspnea is a cardinal symptom of AECOD and a major cause of disability and anxiety associated with the disease. Geriatric patients with AECOPD describe their dyspnea as a feeling of accelerated breathing, chest heaviness, and air hunger, or grasping. It is also linked to simple activities which forces geriatric patient with AECOPD to limit performance of activities of daily living (ADLs) (GOLD, 2020). The cough becomes more severe and strenuous and may be present every day during AECOPD. Sputum production increases and its color may change from white to yellow or green. Furthermore, exercise intolerance in geriatric patients with AECOPD may be caused by prolonged bed rest during hospitalization, elevated cortisol levels, and poor protein balance due to inadequate food intake. Exercise intolerance is also associated with dyspnea due to decreased pulmonary function and impaired oxygenation (Liao et al., 2015; Hurst et al., 2020).

A study done in Egypt in 2018 showed that AECOPD is associated with an increased mortality rate of up to $60 \%$ among geriatric patients (Mehta, 2018). It has a considerable economic burden, a high readmission rate, and a high mortality rate 1year after hospital discharge than those who are not readmitted (Shah et al., 2015; Jacb et al., 2016). According to the statistical records of the respiratory disorders unit and the geriatric medicine unit at The Main University Hospital in Alexandria, Egypt, the monthly admission rate in these units ranges from $70-75$ geriatric patients, with approximately $40-45$ of them diagnosed with
AECOPD (Statistical record of The Main University Hospital, Alexandria, Egypt, 2019 ).

In geriatric patients, the triggering factors of AECOPD include infectious factors (viral or bacterial) (Djamin et al., 2015; Kwak et al., 2016) and noninfectious factors such as smoking, outdoor air pollution, allergens. Medical comorbidities, such as pulmonary embolism, coexisting heart diseases, diabetes mellitus, pneumonia, and acute respiratory distress syndrome, previous history of exacerbations, depression, frailty and non-adherence to treatment are all risk factors associated with AECOPD. These factors increase the risk for hospitalization, treatment failure, and mortality in those geriatric patients (Vijayan, 2013; Djamin et al., 2015).

Management of AECOPD includes pharmacological treatment and nonpharmacological interventions. The goal of AECOPD management is to maintain lung functions, control symptoms, and enhance the quality of life. This can be accomplished through a variety of pharmaceutical agents, including oxygen supply, Beta Agonists \& Anticholinergic, systemic corticosteroids, and antibiotics (GOLD), 2020). Nonpharmacological strategies, such as respiratory rehabilitation nursing interventions, become the standard of care for geriatric patients with AECOPD, by breaking the vicious circle of dyspnea and decreasing activity tolerance (Corhay et al., 2014). Respiratory rehabilitation package is a systematic and holistic intervention that begins with a complete patient assessment and followed by patient-tailored therapies (Fadila, 2007; Corhay et al., 2014).

This package consists of nursing interventions and health teaching. Nursing interventions include walking training, upper limb exercise with deep breathing, pursed lip breathing, and airway clearance, while health teaching includes smoking \& tobacco cessation which is the first step in the treatment of geriatric patients with AECOPD, nutritional support, compliance 
with medications, and psychological counseling (Jones \& Barker, 2018). The proposed respiratory rehabilitation nursing interventions are primarily intended to decrease the severity of symptoms, avoid complications, reduce recurrent hospitalization, and lower the risk of morbidity and mortality. It also helps to minimize the overall cost of the therapeutic regimen, as well as enhances the physical and psychological state of geriatric patients with chronic respiratory disease, which improves their quality of life (Corhay et al., 2014).

In this respect, gerontological nurses have a significant role in caring for geriatric patients with AECOPD and preventing problems. Their role must include problem assessment and identification, planning, and implementation of respiratory rehabilitation nursing interventions. This is by informing patients about the components of these interventions and assisting them to optimize their capacity and increase exercise tolerance. Finally, gerontological nurses play an important role in measuring the effectiveness of nursing interventions by assessing the ability to control and diminish distressing symptoms while achieving the intended goals (Gundry, 2019).

\section{Aim of the Study}

The aim of this study is to determine the effect of respiratory rehabilitation nursing interventions on acute exacerbation symptoms of chronic obstructive pulmonary disease among hospitalized geriatric patients.

\section{Research Hypothesis}

Hospitalized geriatric patients with acute exacerbation symptoms of chronic obstructive pulmonary disease who receive the proposed respiratory rehabilitation nursing interventions exhibit more improvement in symptoms than those who don't receive it.

\section{Materials and Method}

\section{Materials}

Design: This study utilized a quasiexperimental research design (study group and control group).

Settings: The study was conducted in two units affiliated to the Main University Hospital in Alexandria, Egypt, namely; the respiratory disorders unit and the geriatric medicine unit. These units were selected after reviewing the hospital statistical records during the year 2019 which revealed that the average monthly admission rate in these units ranges between 40-45 geriatric patients with AECOPD.

Subjects: The study subjects were selected using the purposive sampling technique and included fifty (50) geriatric patients admitted to the previously mentioned settings, aged 60 years and more, diagnosed with mild or moderate AECOPD, Have intact cognitive function or mild cognitive impairment, have no or mild depression, have blood oxygen concentration ( $\mathrm{SpO} 2)$ not lower than $90 \%$, and diagnosed with dyspnea not caused by heart disease or pulmonary edema.

The sample size was estimated using the EPI info 7.0 program based on the following parameters; population size: 45 over three months, expected frequency: $50 \%$, acceptable error: 5\%, confidence coefficient: $95 \%$, the minimum sample size: 40. The researcher included 50 subjects in the study.

The selected subjects were divided into two equally matched groups; each group included 25 geriatric patients with AECOPD:

- The study group received the proposed respiratory rehabilitation nursing interventions for four consecutive days in addition to the usual hospital care.

- The control group received only the usual hospital care.

Tools: Six tools were used in this study: 


\section{Tool I: Short Portable Mental Status Questionnaire (SPMSQ)}

This tool was developed by (Pfeiffer, 1975). It is a reliable and valid instrument to assess the cognitive function of older adults and consists of 10 questions. Items are summed up for a total score 10. A score from 0-2 indicates no cognitive impairment, 3-4 mild cognitive impairment, 5-7 moderate cognitive impairment and 8-10 sever cognitive impairment. This tool was translated into Arabic language and tested for its validity and reliability by (Abdel Salam, 2012), reliability $r=0.89$.

\section{Tool II: Geriatric Depression Scale Short- Form (GDS-SF)}

GDS-SF is a 15-item self-report instrument developed by (Yesavage et al., 1983) to assess depression and general wellbeing in the elderly. The geriatric patients choose either yes (1) or no (0) for how he/she has felt over the past week. Scores range from 0 to 15 . Items are summed for a total score. A score from 0 to 4 indicates no depression, 5 to 8 mild depression, 9 to 11 moderate depression and 12-15 severe depression. The GDS-SF was translated into Arabic language and proved to be valid and reliable by (Elhusseini, 2013), reliability $\mathrm{r}=0.70$.

Tool III: Socio-demographic and Clinical Data of Hospitalized Geriatric Patients with AECOPD Symptoms Structured Interview Schedule

This tool was developed by the researchers based on review of relevant literature. It included the following:

Part I: Socio-demographic data such as age, sex, level of education, marital status, work status, and monthly income.

Part II: Clinical data such as duration of AECOPD, previous hospitalization within the last year due to AECOPD symptoms, comorbidities, smoking history, sputum clearance, and medical treatment.
Tool IV: The Simplified Cough Score (SCS)

It was developed by the (Respiratory Branch of Chinese Medical Association, 2014) and it was a reliable tool for assessing the severity of cough in geriatric patients $(r=0.74)$. The SCS, which has evolved from the Cough Severity Score (CSS), ranks cough symptoms on a scale of 0 to 3 , making it easier to use.

It consists of two parts referring to symptoms during the day-time and nighttime. During the day-time; $0=\mathrm{No}$ cough, $1=$ Transient cough occasionally during the day-time, $2=$ Frequent cough mildly affecting daily life, and $3=$ Frequent cough severely affecting daily life, During the Night-time; $0=$ No cough, $1=$ Transient cough before sleep or occasional cough during the night, $2=$ Cough mildly affecting night sleep, and $3=$ Cough severely affecting night sleep.

Tool V: The Modified Borg Scale for Perceived Dyspnea

This tool was developed by (Borg, 1982) to assess dyspnea in response to submaximal exercise and treatment. This scale consists of 12 -items and 10 rating scale with descriptive anchors ranging from zero which indicates no dyspnea to ten maximal dyspnea $(0=$ nothing at all, $0.5=$ very, very slight (just noticeable), $1=$ very slight, $2=$ slight, 3 =moderate, $\quad 4=$ somewhat severe, $5 \& 6=$ severe, $7 \& 8=$ very severe, $9=$ very very severe (almost maximal), and 10=maximal. It was translated into Arabic language and proved to be valid and reliable by (Mohammed et al., 2016) reliability $\mathrm{r}=0.94$.

Tool VI: 1-Minute Sit-to-Stand (1- MSTS) $\underline{\text { Test }}$

The 1-MSTS test was developed by (Csuka \& Carty, 1985). It is valuable to assess the level of exercise tolerance in COPD. It was tested for its validity and reliability on geriatric patients by (Vaidya et al., 2016), reliability $\mathrm{r}=0.75$. The patient is asked to stand upright from a chair with standard height of $46 \mathrm{~cm}$ without arm rests and then sit down in the same position as 
many times as possible for 1 minute at a self-paced speed. The number of repetitions is recorded. The higher number of sitting and standing repetitions per minute indicates higher activity tolerance, while a lower in the number indicates lower activity tolerance.

\section{Method}

\section{1- Administrative process:}

- Approval from The Research Ethics Committee (REC) of the Faculty of Nursing, Alexandria University was obtained.

- The necessary approvals were obtained from the responsible authorities.

- The researchers surveyed the statistical records of the previously mentioned settings during 2019, in order to estimate the average number of subjects to be included in the study.

2- The study was executed through three (3) main phases:

\section{I- Preparation phase:}

\section{A- Preparation of the study tools:}

- The Arabic version of tool I and tool II were used in this study in order to select the study subjects.

- Tool III was designed by the researchers after extensive review of relevant literature to assess the sociodemographic and clinical data of the study and control groups.

- The Arabic version of tool V was used in the current study.

- Tool IV and tool VI were translated into Arabic language by the researchers and validated by juries of (5) experts in the related field of the study. Their suggestions and recommendations were taken into consideration. These tools were tested for their reliability, Cronbach's coefficient alpha test was used to ascertain the reliability of tool IV, $\mathrm{r}=0.951$, and a test-retest was used for tool VI, r=0.773.

\section{B- A pilot study:}

- A pilot study was carried out on five (5) geriatric patients with AECOPD; they were not included in the study subjects. It was done to assess the applicability, clarity and feasibility of the study tools, and to estimate the time required for the interview. The necessary modifications were done accordingly.

\section{C- Developing the Proposed Respiratory Rehabilitation Nursing Interventions:}

- After a thorough review of the most recent related literature, the researchers designed the proposed nursing interventions, it included disease awareness, airway clearance, pursed lip breathing exercise, upper limbs exercise with deep breathing, walk training, and health teaching for geriatric patients.

- The proposed package was offered to geriatric patients using an illustrating brochure which was developed by the researchers. This brochure contained illustrative colored pictures and the main points of each nursing intervention.

- At the end of the implemented interventions on the fourth day, this brochure was given to the control group to avoid interfering with the study results and ensure that all study subjects were treated fairly.

D- The researcher assessed each patient individually for cough, sputum expectoration, dyspnea, and exercise tolerance using tools IV, V, and VI one hour before starting the proposed nursing interventions and before getting the usual hospital care for the study group. As for the control group, these measurements were taken one hour before receiving the 
usual hospital care only. These results serve as a baseline data.

\section{II- Implementation phase:}

- The researcher prepared the needed equipment, environment, and the geriatric patient:

- Gloves, sphygmomanometer, stethoscope, pulse oximeter, and tissue paper.

- Reducing external noise and interruptions as much as possible to avoid patient distraction.

- Assuring the geriatric patient that the proposed nursing interventions are safe and would not negatively affect his or her health.

- The proposed nursing interventions were implemented individually for each geriatric patient 24 hours after his/her hospital admission for four consecutive days, twice daily during the morning and afternoon shifts with at least 6 hours between the two shifts.

- The researcher measured the geriatric patient's vital signs immediately before the start of the proposed nursing interventions to ensure the patient's stability.

- The proposed respiratory rehabilitation included a package of six nursing interventions as follows:

1- Disease awareness: The researcher used interactive discussion and used illustrative pictures to clarify the importance of the proposed respiratory rehabilitation, as well as signs and symptoms, risk factors, complications, and pharmacological treatment of AECOPD.

2- Airway clearance: Chest percussion was done by the researcher for each geriatric patient for 2 to 3 minutes to move the sputum into the main bronchi in order to facilitate and increase sputum expectoration.
3- Pursed lip breathing exercise: The patient is asked to sit in bed and place his/her hand on the rib cage, then take a deep breath through the nose and hold it for 2-3 seconds. Then exhale the air slowly through pursed lips. The patient is informed to do the exercise for 10 minutes twice daily.

4- Upper limbs exercise with deep breathing: The researcher asks the geriatric patient to inhale while both arms are raised and exhale when they are down. The patient is informed to do this exercise for 10 minutes twice daily.

5- Walk training: The patient walks in the corridor of the unit near his/her room with the assistance of the researcher. The exercise starts gradually, taking into consideration the patient's tolerance. The patient is asked to repeat the walk training for 10 minutes twice daily.

6- Health teaching: The researcher used an illustrative brochure and videos to teach the patient about the importance of adhering to prescribed medications and steps for using inhalers, proper nutrition and hydration, avoiding risk behaviors such as smoking and passive smoking, and reducing infection and airway irritants. The teaching took around 10 minutes.

\section{II- Evaluation phase:}

- Each geriatric patient in the study group was assessed on the fourth day, one hour after the implementation of the proposed nursing interventions using tools IV, V, and VI. Moreover, geriatric patients in the control group were assessed individually on the fourth day after receiving routine hospital care using the same tools.

- In order to evaluate the effectiveness of the proposed nursing interventions, the researcher compared the differences between the first day and 
the fourth day scores in both the study and control groups.

3- $\quad$ The collection of data covered a period of three months, from the beginning of January 2021 to the first of April 2021.

\section{Ethical considerations:}

An informed written consent was obtained from each participant after clarification of the study purpose. Privacy of the study subjects and confidentiality of the collected data was maintained. The study subjects were informed that their participation is voluntary and that they can withdraw at any time without any penalty.

\section{Statistical Analysis}

The collected data were coded and transformed into specially designed forms as to be suitable for computer feeding and all entered data were verified for any error. Software IBM SPSS version 20.0 was used for the statistical analysis. Descriptive statistics were done using numbers, percentages, arithmetic mean and standard deviation. Cronbach's alpha method and test-re-test were used to measure the reliability. Analytical statistics were done using significance test Chi square test. If more than $20 \%$ of the cells have expected values $<5$ and the level of significance was set as $\leq 0.05$. McNemar and Marginal Homogeneity Test, Student t-Test, Mann Whitney Test, Wilcoxon Signed Ranks Test, and Effect Size Test were used in this study.

\section{Results}

Part 1: Socio-demographic characteristics and clinical data of geriatric patients with AECOPD in the study and control groups:

The age of the geriatric patients in both groups ranged from 60 years to 76 years with a mean $66.48 \pm 5.02$ years for the study group, and 67.28 \pm 4.23 years for the control group. Males were more prevalent in both groups. More than one half of both the study and control groups were married $(60.0 \%$ and
$56.0 \%$ respectively). Illiteracy was prevailing in both groups $(36.0 \%$ and $32.0 \%$ respectively). Skilled workers constituted $88.9 \%$ for the study group and $50.0 \%$ for the control group. The monthly income is reported to be enough by $64.0 \%$ for both groups.

Dyspnea, cough, and wheezes were the main presenting symptoms for all geriatric patients with AECOPD in both groups. This is followed by fatigue was reported by $96.0 \%$ for the study group and $100.0 \%$ for the control group. The duration of AECOD symptoms ranged from 2 to 30 days in both the study and control groups with a mean duration of $9.60 \pm 7.26$ days for the study group and 5.76 \pm 5.28 days for the control group. The difference was statistically significant, $\mathrm{P}=0.012$. Only $8.0 \%$ of the study group was not hospitalized due to AECOPD during the last year, while all those in the control group were hospitalized during this period.

Regarding other medical disorders associated with AECOPD, respiratory diseases accounted for $72.0 \%$ for the study group and $44.0 \%$ for the control group, with a statistical significant difference, $\mathrm{P}=0.045$. Asthma is the most prevalent respiratory disease among the study and the control group $(83.3 \%$ and $54.5 \%$ respectively). Cardiovascular diseases accounted for $52.0 \%$ in the study group and $20.0 \%$ in the control group and the difference was statistically significant, $\quad \mathrm{P}=0.018$. Mucolytic\& expectorant and corticosteroids were consumed by $100.0 \%$ of both groups, while antibiotics was used by $100.0 \%$ of the study group and $96.0 \%$ of the control group, also bronchodilators and oxygen therapy were used by $96.0 \%$ of the study group and $100.0 \%$ of the control group

Part II: Effect of the proposed nursing interventions on AECOPD symptoms among geriatric patients in the study group versus routine hospital care in the control group: 
Table (1) indicates that after the implementation of the proposed respiratory rehabilitation nursing interventions, A statistically significant improvement was observed in sputum color $\mathrm{MCp}=0.024$ and amount $\mathrm{MCp}=<0.001$ among the study subjects, when compared to the control group of those who received only usual hospital care. Furthermore, there was no significant change in consistency of sputum among the subjects in both groups, $\mathrm{P}=0.508$.

Table (2) illustrates that a statistically significant improvement in the severity of cough during day-time and night-time $\mathrm{P}=<0.001$ were reported after the implementation of the proposed nursing interventions by the subjects in the study group compared with those in the control group who received only routine hospital care.

Table (3) clarifies that the severity of dyspnea was considerably reduced among both groups, but the variation between the study and control groups was statistically significant, ${ }^{\mathrm{MC}} \mathrm{p}=<0.001$.

Figure (1) illustrates that there was a statistically significant raise in the mean score of the exercise tolerance level in the study group after nursing interventions (Mean $\pm \mathrm{SD}=4.44 \pm 1.19)$ as compared to its level prior to the implementation of the proposed nursing interventions (Mean $\pm \mathrm{SD}=2.08 \pm 1.15$ ). In relation to the control group, the mean score of exercise tolerance level was lower after receiving routine hospital care $($ Mean $\pm \mathrm{SD}=1.64 \pm 0.91)$ than before (Mean $\pm \mathrm{SD}=1.72 \pm 0.79)$.

Table (4) revealed that the proposed nursing interventions had a greater and more positive effect size on the severity of dyspnea (0.926) than on other acute exacerbation symptoms of COPD. On the other hand, routine hospital care had a low effect on sputum expectoration (0.333) and the severity of dyspnea (0.206) was observed among the control group, and had no effect on the severity of cough during day and night $(0.080,0.011$, respectively) and exercise tolerance level (0.016).

\section{Discussion}

Respiratory rehabilitation is one of the most successful interventions used for AECOPD management. It is a comprehensive intervention that includes, but is not restricted to, exercise training, health teaching, and behavior adjustments. Respiratory rehabilitation aims to lessen the severity of AECOPD symptoms and avoid complications (Spruit et al., 2013; Corhay et al., 2014). Therefore, this study was conducted to determine the effect of respiratory rehabilitation nursing interventions on AECOPD symptoms among hospitalized geriatric patients.

In this regard, the current study has shown promise in terms of reducing the severity of AECOPD symptoms among hospitalized geriatric patients. At the end of the fourth day of the proposed interventions, all of the AECOPD symptoms in the study group were less severe than those in the control group (Table 1, 2, 3 and Figure 1). One of the sound findings of this study is that the proposed nursing interventions had a greater and more positive effect size on the severity of dyspnea than on the severity of other AECOPD symptoms. On the other hand, routine hospital care in the control group had a low effect on sputum expectoration and the severity of dyspnea, but no effect on the severity of cough during day and night as well as the exercise tolerance level (Table 4). These positive findings could be attributable to the successful and timely implementation of a package of six nursing interventions during AECOPD symptoms twice daily for four consecutive days. This is offered to the study group through the use of illustrated colored pictures to cover key educational points. These findings are in harmony with the findings of a study conducted in Taiwan byLiao et al. (2015).

A striking finding of the current study was that the proposed nursing interventions 
significantly improved sputum's color and amount in the study group compared to the control group, where no change occurred, but the variations in sputum consistency between both groups were not statistically significant (Table 1). These results may be due to the application of chest percussion for the study group to move the sputum up into the main bronchi in order to facilitate and increase sputum expectoration. Furthermore, health education was given about the need to boost fluid intake and avoid smoking, while these interventions were not included in the control group's usual hospital care. Variation in sputum consistency may be attributed to the interaction of another factor, such as the effect of mucolytic medications administered to both groups. These findings are in the same line with two studies done in Italy and Taiwan (Clini et al., 2009; Liao et al., 2015).

Auspiciously, after implementing the proposed nursing interventions, a significant improvement in the severity of cough during the day and night in the study group compared to those in the control group, where the result did not change (Table 2). This improvement may be due to the inclusion of pursed lip breathing exercise, which helps to enhance diaphragm respiratory coordination and inspiratory muscle strength, while decreasing coughing frequency. This corresponded to a study conducted in Assiut by Mehany et al. (2016) and a study done in India by Ambali \& Jayanth (2019).

The current study also demonstrated that the proposed nursing interventions had a significant positive effect on the severity of dyspnea in the study group, compared to a minor improvement in the severity of dyspnea in the control group (Table 3). This outcome might be attributed to the pursed lip exercise and upper limb exercise with deep breathing which implemented for the study group, whereas minimal progress in the control group could be attributed to oxygen treatment, which was delivered as part of their usual hospital care. This finding supports a recent European research by Jakob \& Carsten (2020), which found that early pulmonary rehabilitation following AECOPD helps in reducing the severity of dyspnea in hospitalized geriatric patients; while Liao et al. (2015) reported that the control group did not improve after receiving routine hospital care in Taiwan.

Surprisingly, the current study found a significant increase in the exercise tolerance level in the study group post-intervention when compared to its level before. In contrast, post receiving routine hospital care, the exercise tolerance level was lower in the control group (Figure 1). This finding could be attributed to the fact that the study group was encouraged to walk for 10 minutes twice daily. Moreover, other AECOPD symptoms such as cough and dyspnea were reduced, which is useful in enhancing exercise tolerance. On the other hand, the control group reported exercise intolerance as a result of the severity of AECOPD symptoms, which limited their mobility level. These findings are consistent with those of a study conducted in the United Kingdom (UK) by Jones \& Barker (2018) and a study conducted in the USA by Andrea \& Levine (2020).

\section{Conclusion}

According to the findings of this study, the proposed respiratory rehabilitation nursing interventions proved to be effective in reducing the severity of acute exacerbation of chronic obstructive pulmonary disease (AECOPD) symptoms among hospitalized geriatric patients.

\section{Recommendations}

In the light of the present study results, the following are the main recommendations:

- Providing educational materials such as posters and brochures to respiratory disorders units, including brief knowledge of symptoms, risk factors, prevention, and measures 
required for self-care management during an AECOPD episode.

- An interdisciplinary team should design, implement, and supervise a discharge plan of care for geriatric patients with AECOPD in order to reduce the impact of the current acute episode and prevent future relapses. This is accomplished by educating patients on how to reduce AECOPD triggers, as well as the importance of medication adherence and regular follow-up.

- Hospitals' responsible authorities should develop in-service training programs for all nurses and other health care providers who work in respiratory disorders units to update their knowledge and increase their skills in caring for geriatric patients with AECOPD.

\section{Recommended future researches} include:

- The efficacy of a home-based respiratory rehabilitation program with long-term follow-up for geriatric COPD patients in preventing the onset of AECOPD symptoms.

- Generalization of the current research on a larger probability sample obtained from different geographical areas in Egypt.

\section{Acknowledgement}

The authors would like to express their heartfelt gratitude to the heads of the respiratory disorders unit and geriatric medicine unit at The Main University Hospital in Alexandria, Egypt, for their willingness to allow the study to take place. Sincere thanks and appreciation also go to all geriatric patients for their participation, cooperation, and assistance in carrying out this work. This study would not be possible without their assistance and cooperation. 
Table (1): Effect of the proposed nursing interventions on AECOPD symptoms: sputum expectoration (color, consistency, and amount) among geriatric patients in the study group versus routine hospital care in the control group

\begin{tabular}{|c|c|c|c|c|c|c|c|c|c|c|c|c|}
\hline \multirow{4}{*}{$\begin{array}{l}\text { Sputum } \\
\text { expectoration }\end{array}$} & \multirow{2}{*}{\multicolumn{4}{|c|}{$\begin{array}{c}\text { Study group } \\
\text { Nursing interventions }\end{array}$}} & \multirow{2}{*}{\multicolumn{4}{|c|}{$\begin{array}{c}\text { Control group } \\
\text { Assessment }\end{array}$}} & \multirow{2}{*}{\multicolumn{4}{|c|}{ Study vs. control }} \\
\hline & & & & & & & & & & & & \\
\hline & \multicolumn{2}{|c|}{ Before } & \multicolumn{2}{|c|}{ After } & \multicolumn{2}{|c|}{$\begin{array}{c}\text { On the first } \\
\text { day }\end{array}$} & \multicolumn{2}{|c|}{$\begin{array}{c}\text { On the fourth } \\
\text { day }\end{array}$} & \multicolumn{2}{|c|}{ On the first day } & \multicolumn{2}{|c|}{$\begin{array}{c}\text { On the fourth } \\
\text { day }\end{array}$} \\
\hline & $\begin{array}{l}\text { no. } \\
=25\end{array}$ & $\%$ & $\begin{array}{c}\text { no. } \\
=25\end{array}$ & $\%$ & $\begin{array}{l}\text { no. } \\
=25\end{array}$ & $\%$ & $\begin{array}{l}\text { no. } \\
=25\end{array}$ & $\%$ & $\chi^{2}$ & $\mathbf{p}_{1}$ & $\chi^{2}$ & $\mathbf{p}_{1}$ \\
\hline \multicolumn{13}{|l|}{ Color of sputum } \\
\hline Transparent & 10 & 40.0 & 11 & 44.0 & 6 & 24.0 & 6 & 24.0 & \multirow{4}{*}{7.838} & \multirow{4}{*}{$\begin{array}{l}{ }_{\mathrm{MC}}^{\mathrm{M}}= \\
0.047\end{array}$} & \multirow{4}{*}{$9.257^{*}$} & \multirow{4}{*}{$\begin{array}{l}{ }_{\mathrm{MC}}^{\mathrm{p}}= \\
0.024^{*}\end{array}$} \\
\hline White & 5 & 20.0 & 5 & 20.0 & 14 & 56.0 & 14 & 56.0 & & & & \\
\hline Yellow & 5 & 20.0 & 6 & 24.0 & 1 & 4.0 & 1 & 4.0 & & & & \\
\hline Green & 5 & 20.0 & 3 & 12.0 & 4 & 16.0 & 4 & 16.0 & & & & \\
\hline $\mathrm{p}_{2}$ & \multicolumn{4}{|c|}{${ }^{\mathrm{MH}} \mathrm{p}=0.102$} & \multicolumn{4}{|c|}{${ }^{\mathrm{MH}} \mathrm{p}=1.000$} & & & & \\
\hline \multicolumn{13}{|l|}{$\begin{array}{l}\text { Consistency of } \\
\text { sputum }\end{array}$} \\
\hline Thick & 21 & 84.0 & 5 & 20.0 & 12 & 48.0 & 7 & 28.0 & \multirow{2}{*}{$7.219^{*}$} & \multirow{2}{*}{$0.007^{*}$} & \multirow{2}{*}{0.439} & \multirow{2}{*}{0.508} \\
\hline Thin & 4 & 16.0 & 20 & 80.0 & 13 & 52.0 & 18 & 72.0 & & & & \\
\hline $\mathbf{p}_{2}$ & \multicolumn{4}{|c|}{${ }^{\mathrm{McN}} \mathrm{p}<0.001^{*}$} & \multicolumn{4}{|c|}{$\mathrm{McN}_{\mathrm{p}}=0.063$} & & & & \\
\hline Amount of sputum & & & & & & & & & \multirow{4}{*}{4.075} & \multirow{5}{*}{$\begin{array}{l}{ }^{\mathrm{MC}} \mathrm{p}= \\
0.155\end{array}$} & \multirow{4}{*}{$15.870^{*}$} & \multirow{4}{*}{$\begin{array}{c}{ }^{\mathrm{MC}} \mathrm{p}= \\
<0.001\end{array}$} \\
\hline Large amount & 10 & 40.0 & 1 & 4.0 & 12 & 48.0 & 8 & 32.0 & & & & \\
\hline Moderate amount & 11 & 44.0 & 12 & 48.0 & 13 & 52.0 & 16 & 64.0 & & & & \\
\hline Small amount & 4 & 16.0 & 12 & 48.0 & 0 & 0.0 & 1 & 4.0 & & & & \\
\hline $\mathbf{p}_{2}$ & \multicolumn{4}{|c|}{${ }^{\mathrm{MH}} \mathrm{p}=0.001^{*}$} & \multicolumn{4}{|c|}{${ }^{\mathrm{MH}} \mathrm{p}=0.025^{*}$} & & & & \\
\hline
\end{tabular}

Table (2): Effect of the proposed nursing interventions on AECOPD symptoms: the severity of cough (day-time and night-time) among geriatric patients in the study group versus routine hospital care in the control group

\begin{tabular}{|c|c|c|c|c|c|c|c|c|c|c|c|c|}
\hline \multirow{4}{*}{ Severity of cough } & \multicolumn{4}{|c|}{ Study group } & \multicolumn{4}{|c|}{ Control group } & \multirow{2}{*}{\multicolumn{4}{|c|}{ Study vs. control }} \\
\hline & \multicolumn{4}{|c|}{ Nursing interventions } & \multicolumn{4}{|c|}{ Assessment } & & & & \\
\hline & \multicolumn{2}{|c|}{ Before } & \multicolumn{2}{|c|}{ After } & \multicolumn{2}{|c|}{$\begin{array}{l}\text { On the first } \\
\text { day }\end{array}$} & \multicolumn{2}{|c|}{$\begin{array}{c}\text { On the } \\
\text { fourth day }\end{array}$} & \multicolumn{2}{|c|}{ On the first day } & \multicolumn{2}{|c|}{$\begin{array}{c}\text { On the fourth } \\
\text { day }\end{array}$} \\
\hline & $\begin{array}{c}\text { no. }=2 \\
5\end{array}$ & $\%$ & $\begin{array}{c}\text { no. }=2 \\
5\end{array}$ & $\%$ & $\begin{array}{c}\text { no. }=2 \\
5\end{array}$ & $\%$ & $\begin{array}{c}\text { no. }=2 \\
5\end{array}$ & $\%$ & $\chi^{2}$ & $\mathbf{p}_{1}$ & $\chi^{2}$ & $\mathbf{p}_{1}$ \\
\hline Day-time & & & & & & & & & & & & \\
\hline No cough & 0 & 0.0 & 4 & 16.0 & 0 & 0.0 & 0 & 0.0 & & & & \\
\hline $\begin{array}{l}\text { Transient cough occasionally during the day- } \\
\text { time }\end{array}$ & 1 & 4.0 & 18 & 72.0 & 1 & 4.0 & 3 & 12.0 & 3.200 & 0.192 & $30.725^{*}$ & $<0.001^{*}$ \\
\hline Frequent cough mildly affecting daily life & 8 & 32.0 & 3 & 12.0 & 14 & 56.0 & 14 & 56.0 & & & & \\
\hline Frequent cough severely affecting daily life & 16 & 64.0 & 0 & 0.0 & 10 & 40.0 & 8 & 32.0 & & & & \\
\hline $\mathrm{MHp}_{2}$ & \multicolumn{4}{|c|}{$<0.001^{*}$} & \multicolumn{4}{|c|}{$<0.001^{*}$} & & & & \\
\hline Night-time & & & & & & & & & \multirow{5}{*}{3.900} & \multirow{5}{*}{0.258} & \multirow{5}{*}{$14.923^{*}$} & \multirow{5}{*}{$<0.001^{*}$} \\
\hline No cough & 1 & 4.0 & 6 & 24.0 & 3 & 12.0 & 1 & 4.0 & & & & \\
\hline $\begin{array}{l}\text { Transient cough before sleep or occasional } \\
\text { cough during the night }\end{array}$ & 0 & 0.0 & 14 & 56.0 & 2 & 8.0 & 6 & 24.0 & & & & \\
\hline Cough mildly affecting night sleep & 12 & 48.0 & 5 & 20.0 & 13 & 52.0 & 13 & 52.0 & & & & \\
\hline Cough severely affecting night sleep & 12 & 48.0 & 0 & 0.0 & 7 & 28.0 & 5 & 20.0 & & & & \\
\hline $\mathrm{MHp}_{2}$ & \multicolumn{4}{|c|}{0.157} & \multicolumn{4}{|c|}{0.593} & & & & \\
\hline
\end{tabular}

p1: $p$ value for comparing between the studied groups in each of pre-test and post-test

2: $p$ value for comparing between pre-test and post-test in each of study and control group

$\chi^{2}$ : Chi square test MC: Monte Carlo $\quad$ MH: Marginal Homogeneity Test $\quad$ *: Statistically significant at $p \leq 0.05$ 
Table (3): Effect of the proposed nursing interventions on AECOPD symptoms: the severity of dyspnea among geriatric patients in the study group versus routine hospital care in the control group

\begin{tabular}{|c|c|c|c|c|c|c|c|c|c|c|c|c|}
\hline \multirow{4}{*}{ Severity of dyspnea } & \multirow{2}{*}{\multicolumn{4}{|c|}{$\begin{array}{c}\text { Study group } \\
\text { Nursing interventions }\end{array}$}} & \multirow{2}{*}{\multicolumn{4}{|c|}{$\begin{array}{c}\text { Control group } \\
\text { Assessment } \\
\end{array}$}} & \multirow{2}{*}{\multicolumn{4}{|c|}{ Study vs. control }} \\
\hline & & & & & & & & & & & & \\
\hline & \multicolumn{2}{|c|}{ Before } & \multicolumn{2}{|c|}{ After } & \multicolumn{2}{|c|}{$\begin{array}{c}\text { On the first } \\
\text { day }\end{array}$} & \multicolumn{2}{|c|}{$\begin{array}{c}\text { On the } \\
\text { fourth day }\end{array}$} & \multicolumn{2}{|c|}{$\begin{array}{c}\text { On the first } \\
\text { day }\end{array}$} & \multicolumn{2}{|c|}{$\begin{array}{c}\text { On the fourth } \\
\text { day }\end{array}$} \\
\hline & $\begin{array}{c}\text { no. }= \\
25\end{array}$ & $\%$ & $\begin{array}{c}\text { no. }= \\
25\end{array}$ & $\%$ & $\begin{array}{c}\text { no. }= \\
25\end{array}$ & $\%$ & $\begin{array}{c}\text { no. }= \\
25\end{array}$ & $\%$ & $\chi^{2}$ & $\mathbf{p}_{1}$ & $\chi^{2}$ & $\mathbf{p}_{1}$ \\
\hline Nothing at all & 0 & 0.0 & 0 & 0.0 & 0 & 0.0 & 0 & 0.0 & & & & \\
\hline $\begin{array}{l}\text { Very, Very slight } \\
\text { (just noticeable) }\end{array}$ & 0 & 0.0 & 3 & 12.0 & 0 & 0.0 & 0 & 0.0 & & & & \\
\hline Very slight & 0 & 0.0 & 1 & 4.0 & 0 & 0.0 & 0 & 0.0 & & & & \\
\hline Slight & 1 & 4.0 & 9 & 36.0 & 2 & 8.0 & 2 & 8.0 & & & & \\
\hline Moderate & 1 & 4.0 & 9 & 36.0 & 6 & 24.0 & 4 & 16.0 & $\chi^{2}=$ & ${ }^{\mathrm{MC}} \mathrm{p}=$ & $\chi^{2}=$ & \\
\hline Somewhat severe & 3 & 12.0 & 3 & 12.0 & 10 & 40.0 & 7 & 28.0 & $14.152^{*}$ & $0.009^{*}$ & $23.370^{*}$ & $<0.001^{*}$ \\
\hline Severe & 7 & 28.0 & 0 & 0.0 & 3 & 12.0 & 8 & 32.0 & & & & \\
\hline Very severe & 10 & 40.0 & 0 & 0.0 & 4 & 16.0 & 1 & 4.0 & & & & \\
\hline $\begin{array}{l}\text { Very, Very severe } \\
\text { (almost maximal ) }\end{array}$ & 3 & 12.0 & 0 & 0.0 & 0 & 0.0 & 1 & 4.0 & & & & \\
\hline Maximal & 0 & 0.0 & 0 & 0.0 & 0 & 0.0 & 2 & 8.0 & & & & \\
\hline
\end{tabular}

p1: $p$ value for comparing between the studied groups in each of pre-test and post-test

2: $p$ value for comparing between pre-test and post-test in each of study and control group

ఒ2: Chi square test $\quad$ MC: Monte Carlo MH: Marginal Homogeneity Test $\quad$ *: Statistically significant at $p \leq 0.05$

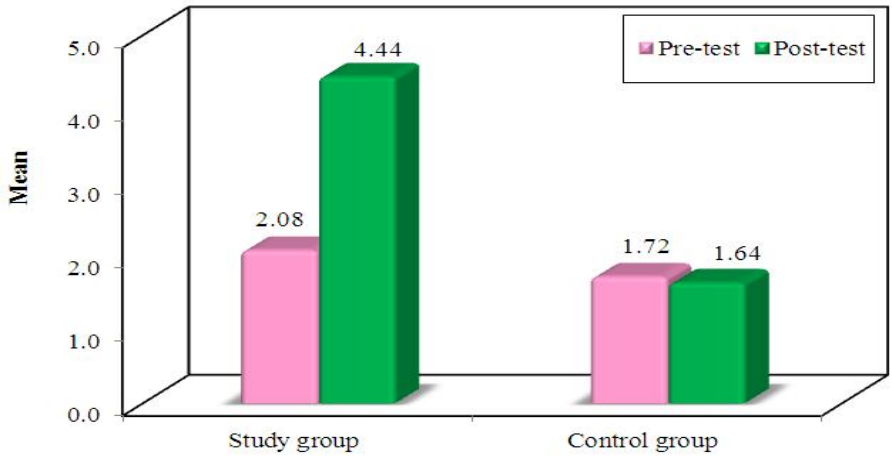

Figure (1): Effect of the proposed nursing interventions on AECOPD symptoms: exercise tolerance level among geriatric patients in the study group versus routine hospital care in the control group

Table (4): Effect size of respiratory rehabilitation nursing interventions on acute exacerbation symptoms of COPD (sputum expectoration, severity of cough, severity of dyspnea, and exercise tolerance level) among geriatric patients in the study group versus routine hospital care in the control group

\begin{tabular}{|c|c|c|c|c|}
\hline \multirow{2}{*}{$\begin{array}{l}\text { Acute exacerbation symptoms of } \\
\text { COPD }\end{array}$} & \multicolumn{2}{|c|}{$\begin{array}{l}\text { Study group } \\
(\text { no. }=25)\end{array}$} & \multicolumn{2}{|c|}{$\begin{array}{c}\text { Control group } \\
(\text { no. }=25)\end{array}$} \\
\hline & Effect size eta $^{2}$ & Level & Effect size eta $^{2}$ & Level \\
\hline Sputum expectoration & 0.518 & $\begin{array}{l}\text { Intermediate } \\
\text { Effect }\end{array}$ & 0.333 & Low Effect \\
\hline $\begin{array}{l}\text { Severity of cough } \\
\text { Day-time } \\
\text { Night-time }\end{array}$ & $\begin{array}{l}0.921 \\
0.810\end{array}$ & $\begin{array}{l}\text { High Effect } \\
\text { High Effect }\end{array}$ & $\begin{array}{l}0.080 \\
0.011\end{array}$ & $\begin{array}{l}\text { No effect } \\
\text { No effect }\end{array}$ \\
\hline Severity of dyspnea & 0.926 & High Effect & 0.206 & Low Effect \\
\hline Exercise tolerance level & 0.854 & High Effect & 0.016 & No effect \\
\hline
\end{tabular}

Effect size to determine program effect size Cohen d' was used (eta $\left.{ }^{2}\right)$.

No effect $<0.2 \quad$ Low Effect $0.2-<0.5 \quad$ Intermediate Effect $0.5-<0.8 \quad$ High Effect $>0.8$. 


\section{References}

- Abdel Salam, R. (2012). Effect of Multisensory Stimulation on Cognitive and Physical Functions of Institutionalized Elders. Unpublished Doctorate Thesis, Faculty of Nursing, Alexandria University.

- Ambali, A., \& Jayanth, S. (2019). Acute exacerbation of chronic obstructive pulmonary disease in older people. of Geriatric Education and Medical Sciences Journal, 6 (1), 2-8.

- Andrea, R., \& Levine, M. (2020). Overview of Pulmonary Rehabilitation. Available at: https://www.msdmanuals.com. Retrieved on $08 / 10 / 2020$.

- Borg, G. A. (1982). Psychophysical bases of perceived exertion. Medicine and science in sports and exercise Journal, 14 (5), 377-81.

- Csuka, M., \& McCarty, D. J. (1985). Simple method for measurement of lower extremity muscle strength. The American Journal of Medicine, 78 (1), 77-81.

- Clini, E. M., Crisafulli, E., Costi, S., Rossi, G., Lorenzi, C., Fabbri, L. M., \& Ambrosino, N. (2009). Effects of early inpatient rehabilitation after acute exacerbation of COPD. Respiratory Medicine Journal, 103 (10), 1526-31.

- Corhay, J. L., Dang, D. N., Van Cauwenberge, H., \& Louis, R. (2014). Pulmonary rehabilitation and COPD: providing patients a good environment for optimizing therapy. International Journal of Chronic Obstructive pulmonary Disease, 9, 27-39.

- Djamin, R. S., Uzun, S., Snelders, E., Kluytmans, J. J., Hoogsteden, H. C., Aerts, J. G., \& Van Der Eerden, M. M. (2015). Occurrence of virus-induced COPD exacerbations during four seasons. Infected Diseases Journal, 47(2), 96-100.

- Elhusseini, S. (2013). The Effect of SelfCare Interventions on Quality of Life of Older Adults with Heart Failure. Published Doctorate Thesis, Faculty of Nursing, Alexandria University.
- Fadila, D. (2007). Coping behaviors of elderly patients with chronic obstructive pulmonary disease. Published Master Thesis, Faculty of Nursing, Alexandria University.

- Gundry, S. (2019). COPD: Management and Nursing Care. Respiratory Journal, 5, 48-51.

- Global Initiative for Chronic Obstructive Lung Disease (GOLD). (2020). Global strategy for the diagnosis, management, and prevention of COPD, 3(8), 1-127.

- Hurst, J. R., Skolnik, N., Hansen, G. J., Anzueto, A., Donaldson, G. C., Dransfield, M. T., \& Varghese, P. (2020). Understanding the impact of chronic obstructive pulmonary disease exacerbations on patient health and quality of life. European Journal of Iinternal Medicine, 73, 1-6.

- Jacob, E., Simmering, M., Linnea, A., Polgreen, P., \& Alejandro, P. (2016). Identifying Patients with COPD at High Risk of Readmission. Journal of the COPD Foundation, 3 (4), 729-38.

- Jones, S. E., Barker, R. E., Nolan, C. M., Patel, S., Maddocks, M., \& Man, W. D. C. (2018). Pulmonary rehabilitation in patients with an acute exacerbation of chronic obstructive pulmonary disease. Journal of Thoracic Disease, 10 (12), 1390-99.

- Jakob, L., \& Carsten, B. (2020). Early pulmonary rehabilitation after acute exacerbation of COPD. European Respiratory Journal, 6 (1), 1-10.

- Kwak, H. J., Park, D. W., Kim, J. E., Park, M. K., Koo, G. W., Park, T. S., \& Kim, S. H. (2016). Prevalence and Risk Factors of Respiratory Viral Infections in Exacerbations of Chronic Obstructive Pulmonary Disease. The Tohoku Journal of Experimental Medicine, 240 (2), 131-39.

- Lai, K. (2014). Chinese National Guidelines on Diagnosis and Management of Cough: consensus and controversy. Journal of Thoracic Disease, 6 (7), 683-88. 
- Liao, L., Chen, K., \& Chung, W. (2015). Efficacy of a respiratory rehabilitation exercise training package in hospitalized elderly patients with acute exacerbation of COPD. International Journal of COPD, 10 , 1703-9.

- Mehany, M., Elaal, E., Ghanem, M., \& tolba,K.. (2016). Effect of Specific Nursing Intervention on Respiratory Status of Chronic Obstructive Pulmonary Disease (COPD) During Acute Exacerbation. Journal of Nursing \& Health Sciences, 5 (2), 77-87.

- Mohammed, M., \& Hani, L. (2016). Reliability and validity of an Arabic version of the dyspnea-12 questionnaire for Saudi nationals with chronic obstructive pulmonary disease. The Journal of Thoracic Disease, 10 (2), 1-6.

- Mehta, A. (2018). Predictors of mortality in patients with acute exacerbation of chronic obstructive pulmonary disease requiring ICU admission. The Egyptian Journal of Chest Diseases and Tuberculosis, 67 (4), 361-67.

- Pfeiffer, E. (1975). A short portable mental status questionnaire for the assessment of organic brain deficit in elderly patients. Journal of the American Geriatrics Society, 23 (10), 433-41.

- Spruit, M. A., Singh, S. J., Garvey, C., ZuWallack, R., Nici, L., Rochester, C., \&. Wouters, E. F. (2013). An official American Thoracic Society/European Respiratory Society statement: key concepts and advances in pulmonary rehabilitation. American Journal of Respiratory and Critical Care Medicine, 188 (8), 13-64.
- Shah, T., Churpek, M. M., Coca Perraillon, M., \& Konetzka, R. T. (2015). Understanding why patients with COPD get readmitted: a large national study to delineate the Medicare population for the readmissions penalty expansion. Chest Journal, 147(5), 1219-26.

- Statistical record of the chest diseases and Geriatric Medicine Unite of The Main University Hospital in Alexandria, Egypt, 2019.

- Vijayan, V. K. (2013). Chronic obstructive pulmonary disease. The Indian Journal of Medical Rresearch, 137 (2), 251-69.

- Vaidya, T., de Bisschop, C., Beaumont, M., Ouksel, H., Jean, V., Dessables, F., \& Chambellan, A. (2016). Is the 1-minute sitto-stand test a good tool for the evaluation of the impact of pulmonary rehabilitation? Determination of the minimal important difference in COPD. International Journal of Chronic Obstructive Pulmonary Disease, 11, 2609-16.

- Yesavage, J. A., Brink, T. L., Rose, T. L., Lum, O., Huang, V., Adey, M., \& Leirer, V. O. (1983). Development and validation of a geriatric depression screening scale: a preliminary report. Journal of Psychiatric Research, 17(1), 37-49. 